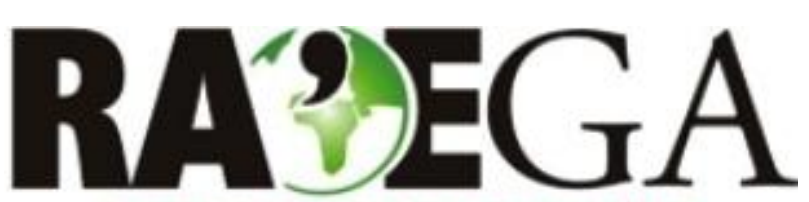

O ESPACOO GEOGRÁFICO EM ANÁLISE

\title{
A CARTOGRAFIA PROSPECTIVA E A GERAÇÃO DE MAPAS PREDITIVOS DO USO E COBERTURA DA TERRA - ESTUDO DE CASO: PERÍMETRO URBANO DE PARANAGUÁ - PARANÁ - BRASIL
}

\section{THE PROSPECTIVE CARTOGRAPHY AND THE GENERATION OF LAND USE AND LAND COVER PREDICTIVE MAPS - CASE STUDY: PARANAGUA URBAN AREA- PARANA - BRAZIL}

\author{
Arnaldo Eugênio Ricobom \\ Professor da Universidade Federal do Paraná (UFPR) \\ Departamento de Geografia \\ Curitiba, $P R$ \\ e-mail: ricobom@ufpr.br \\ Sony Cortese Caneparo \\ Professora da Universidade Federal do Paraná (UFPR) \\ Departamento de Geografia \\ Curitiba, $P R$ \\ e-mail:sony@ufpr.br
}

\section{Recebido em: 06/03/2013}

Aceito em: 04/04/2014

\section{Resumo}

O objetivo deste artigo é descrever a produção de mapas preditivos, dentro da Cartografia Prospectiva, confeccionados com o auxílio dos Sistemas de Informação Geográfica (SIG), por intermédio da geração de um modelo têmporo-espacial. Essa modelagem emprega duas técnicas consecutivas, a dos algoritmos da cadeia de Markov de $2^{\text {a }}$ ordem e a dos Autômatos Celulares (CA). A modelagem dos algoritmos da Cadeia de Markov de $2^{\underline{a}}$ ordem mostra como o sistema evoluirá no tempo, já a modelagem dos Autômatos Celulares (CA) mostra qual o espaço (tamanho, forma e direção) que um sistema ocupará futuramente. Para o desenvolvimento desta modelagem foi utilizado o software IDRISI - ANDES. A área piloto escolhida foi o perímetro urbano de Paranaguá, para o qual foram confeccionados mapas originais de uso e ocupação da terra, para os anos de 1980, 
2003, 2006 e 2009. Os resultados das modelagens foram os mapas preditivos têmporo-espaciais para os anos de 2003, 2006 e 2009. Tais mapas preditivos foram comparados, avaliados e validados com os originais para estas datas. Os resultados demonstraram que as duas técnicas de modelagem aplicadas consecutivamente são eficientes para a geração de mapas preditivos, que mostrem a projeção de dinâmicas têmporo-espaciais, contudo recomenda-se que os resultados também sejam analisados mediante o conhecimento geográfico de cada área.

Palavras-chave: Cartografia prospectiva; SIG; Cadeia de Markov; Autômato Celular; Modelo de crescimento têmporo-espacial.

\begin{abstract}
The purpose of this article is to describe the production of predictive maps within the Prospective Cartography made with the assistance of Geographic Information Systems (GIS), through the generation of a temporal-spatial model. This model employs two consecutive techniques, 2nd order Markov chain algorithms and the Cellular Automata (CA). The 2nd order Markov chain algorithms modeling shows how the system will evolve in time, whereas the cellular automata modeling (CA) shows which spaces (size, shape and direction) the system will occupy future. To develop this modeling was used the software IDRISI-ANDES. The pilot area selected was the urban area of Paranagua, for which original maps of land use and land cover were made for the years 1980, 2003, 2006 and 2009. The results of the modeling were the temporal-spatial predictive maps for the years 2003, 2006 and 2009. These predictive maps were compared, evaluated and validated with the originals for these dates. The results showed that the two modeling techniques applied consecutively are efficient for the generation of predictive maps, showing the projection of temporal-spatial dynamics, however it is recommended that the results be also analyzed by the geographical knowledge of each area.
\end{abstract}

Keywords: Prospective Cartography, GIS, Markov Chain, Cellular Automata, temporal-spatial growth model.

\title{
INTRODUÇÃO
}

A Cartografia Prospectiva vem despontando como uma técnica eficaz, no auxílio para a previsão de cenários futuros, da organização espacial. A construção do documento cartográfico prospectivo, em forma de mapeamento preditivo é baseada na aplicação da metodologia da geração de modelos dinâmicos têmporoespaciais, advinda da aplicação dos mais recentes avanços tecnológicos, nos Sistemas de Informação Geográfica (SIG). 
A cartografia prospectiva e a geração de mapas preditivos do uso e cobertura da terra estudo de: caso perímetro urbano de Paranaguá

Os mapas preditivos têm por finalidade apresentar o desenho futuro do arranjo da distribuição espacial, originária das tendências da atual dinâmica espacial, instalada em áreas da superfície terrestre, que provocam as mudanças dos fenômenos geográficos, naturais, humanos e socioeconômicos, em um determinado lugar.

A mudança do uso e cobertura da terra é um processo têmporo-espacial dinâmico que, ao ser instalado sobre determinada área, passa a ser um processo complexo, não sendo uma ação simples de ser descrita ou de ser prevista. Ainda, modelar a sua tendência futura também vem a ser um desafio, pois há a intervenção de fatores tais como, políticos, de gestão, econômicos, culturais, do comportamento humano e ambiental, que fazem com que essa dinâmica de mudança, instaurada sobre uma área, se torne um sistema geográfico complexo.

A tentativa de se prever o rumo e os resultados dos processos de mudanças de sistemas geográficos complexos, como as mudanças do uso e cobertura da terra, já foi alvo de muitas pesquisas. Entre autores que abordam tais modelos, pode citarse: Chorley e Haggett (1971); Tobler, (1979); Burrough (1998); Batty, Xie; Sun (1999); Rocha, Sousa, Tenedório (2001/02); Almeida (2003); Almeida, Monteiro e Câmara (2007); e Ferreira et al. (2010).

Nos últimos anos, os avanços tecnológicos na área da informática, possibilitaram não apenas análises espaciais automatizadas, através dos Sistemas de Informação Geográfica (SIG), mas também a geração de modelos dinâmicos têmporo-espaciais. Estes últimos se tornaram possíveis por intermédio do emprego de determinados algoritmos estatísticos, muitas vezes em conjunto com ferramentas utilizadas para representar sistemas evolutivos, estudados dentro da teoria da computabilidade, passando a produzir os chamados mapas preditivos, que são as bases da Cartografia Prospectiva.

Entre as opções de software utilizadas para esse fim, destaca-se o IDRISI, o qual em suas mais de 200 rotinas apresenta especificamente duas das quais são técnicas contíguas de modelagem têmporo-espacial. A primeira é a técnica da modelagem temporal, desenvolvida pela a aplicação dos algoritmos da cadeia de Markov de $2^{\underline{a}}$ ordem, que mostra como um sistema geográfico complexo evoluirá no 
tempo, e a segunda técnica da aplicação da dinâmica dos Autômatos Celulares (CA), advinda da teoria da computabilidade, que representa sistemas evolutivos, aqui empregados para prever a evolução espacial (tamanho forma e direção) que um sistema geográfico complexo ocupará futuramente.

Desta forma, no presente artigo se objetiva descrever a produção de mapas preditivos, dentro da Cartografia Prospectiva, confeccionados com o auxílio dos Sistemas de Informação Geográficas (SIG), por intermédio da geração de um modelo têmporo-espacial, empregando duas técnicas contíguas de modelagem: a dos algoritmos da cadeia de Markov de $2^{\underline{a}}$ ordem, e a dos Autômatos Celulares (CA), no perímetro urbano de Paranaguá, para os anos de 2003, 2006 e 2009.

\section{ÁREA DE ESTUDO}

Em função de suas peculiaridades, fora escolhida como área piloto para 0 presente trabalho o Perímetro Urbano do Município de Paranaguá, onde se destacam as seguintes características: espacial (situação geográfica - litoral do Paraná); ambiental (a área contém ambientes ecologicamente frágeis, protegidos por leis ambientais que limitam espacialmente o crescimento urbano) e socioeconômica (o Porto de Paranaguá é um dos maiores do país).

O município de Paranaguá situa-se na porção leste do estado do Paraná, mais precisamente no litoral. A área territorial do município é de 806.225 km², apresentando áreas de terras descontínuas fragmentadas pela Baía de Paranaguá, bem como diversas ilhas, sendo tais partes integrantes da área do município (Figura 01).

Segundo o IBGE (2011), o município apresentava em 2010, uma população de 140.469 habitantes, sendo a maioria concentrada no perímetro urbano do município, onde residem 96,38\% da população (135.386 habitantes). O território rural de Paranaguá é pouco expressivo em número de habitantes, pois ali se encontram apenas $3,62 \%$ da população total (5.083 habitantes). 
A cartografia prospectiva e a geração de mapas preditivos do uso e cobertura da terra estudo de: caso perímetro urbano de Paranaguá

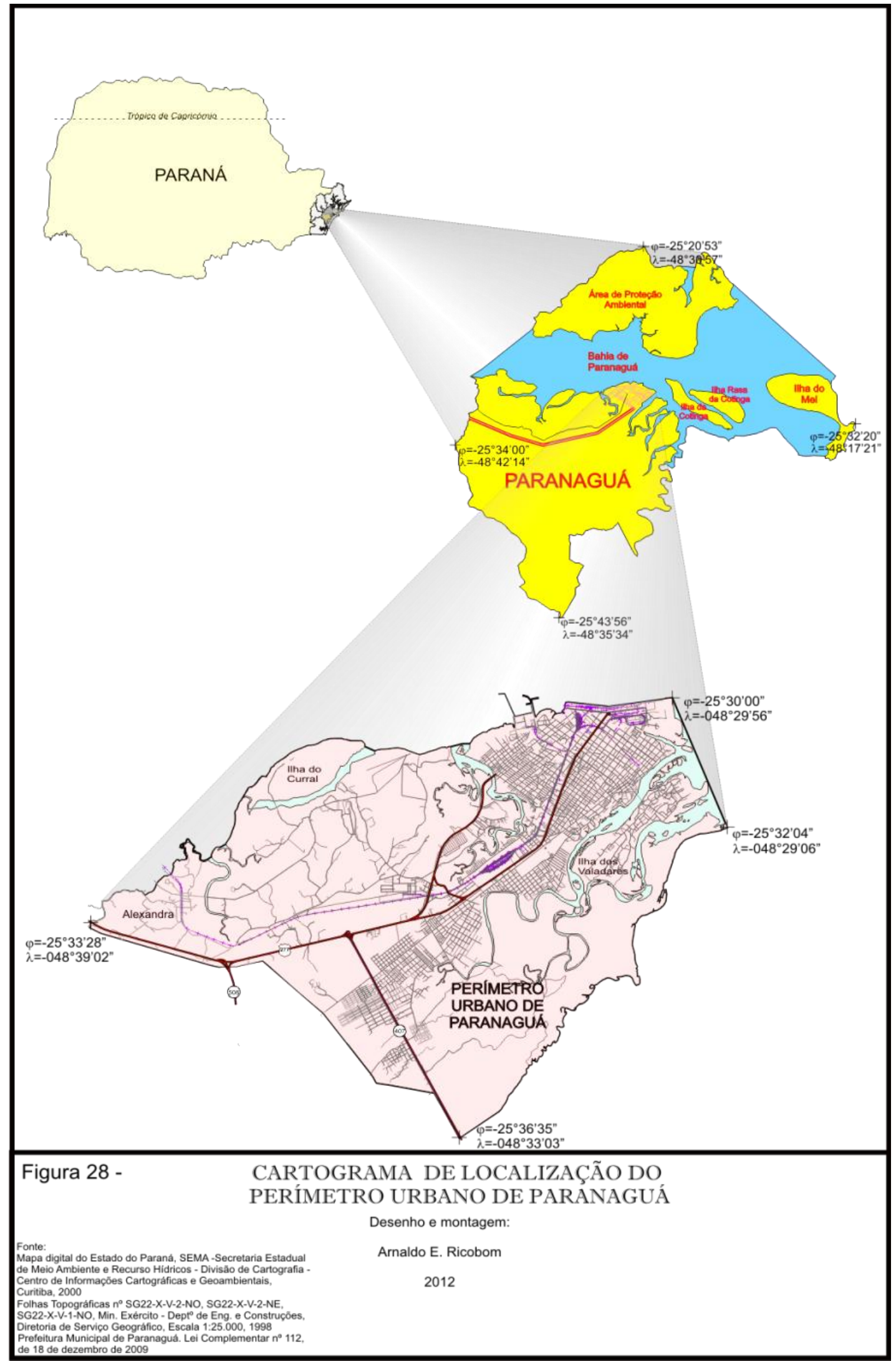

Figura 01: Cartograma de localização do perímetro urbano de Paranaguá.

R. Ra'e Ga - Curitiba, v.31, p.227-259, Ago/2014 
A cartografia prospectiva e a geração de mapas preditivos do uso e cobertura da terra estudo de: caso perímetro urbano de Paranaguá

Para Tramujas (1996), Paranaguá, "nasceu porto, vive porto, respira porto e continuará porto". Tudo na cidade até o momento gira em torno do porto, sendo este responsável pela movimentação de milhares de toneladas de carga/ano e pelo emprego de cerca de $60 \%$ da população local.

O crescimento urbano radial de Paranaguá é limitado por barreiras naturais, sendo que o centro da cidade está situado dentro de um trinário, formado pelas margens do rio Itiberê no lado leste, o rio Emboguaçu no lado oeste, a baía com o cais do porto e toda a sua a infraestrutura na parte norte, que formam barreiras naturais à expansão urbana, sobrando para este fim apenas a parte sudoeste, que segue a direção da rodovia BR 277 e a parte sul, na direção da PR 407 - Estrada das Praias, com ressalva da existência às margens desta rodovia do Parque Floresta Estadual do Palmito, criada pelo decreto 4.493 de 17 de junho de 1998, com 530 hectares.

\section{A CONFECÇÃO DOS MAPAS BASES (ORIGINAIS)}

Para a confecção dos mapas originais do uso e cobertura da terra, dos tempos passados, foram utilizadas fotografias aéreas e imagens de satélite, que cobriam o perímetro urbano de Paranaguá, especificadas as seguir:

Fotografias do ano 1980, escala 1:25.000, pancromáticas, formato $23 \mathrm{x}$ $23 \mathrm{~cm}$, faixa 1 (51.454 até 51.458), faixa 2 (51.411 até 51.414$)$, faixa 3 (51.516 até 51.520), tomadas pela Aerosul S.A, em convênio com o ITC - PR;

Fotografias do ano 1996, escala 1:60.000, pancromáticas, formato $23 \mathrm{x}$ $23 \mathrm{~cm}$, faixa 1 (292), faixa 2 (331), tomadas pela 1ㄹ DL - DSG;

Fotografias do ano 2003, escala 1:25.000, coloridas, formato $23 \times 23$ $\mathrm{cm}$, faixa 1 (1.889 até 1.893), faixa 2 (1.922 até 1.927), faixa 3 (1.948 até 1.953), tomadas pela SEMA/PNMA-II/ FIDUCIAL LTDA;

Imagens do Google Earth- da região que cobre o perímetro urbano de Paranaguá, em escala aproximada de 1:25.000, datada de maio de 2006, a partir de captura digital realizada em setembro de 2011, do software http://www.google.com.br/intl/pt-BR/earth/index.html; 
A cartografia prospectiva e a geração de mapas preditivos do uso e cobertura da terra estudo de: caso perímetro urbano de Paranaguá

Imagens satélite SPOT-5 - da região de Paranaguá, com resolução espacial de 5 metros, de 2005, cedida a equipe da UFPR que elaborou 0 Plano Diretor de Desenvolvimento Integrado de Paranaguá (PDDI), pelo Programme International de Coopération Scientifique AGEPAR au CNRS, France;

Imagens satélite CBERS_2B_HRC_2009 - da região de Paranaguá CBERS_2B_HRC_20090419_155_A_129_1_L2_BAND1_geo, com resolução espacial de 30 metros, cedida pela Secretaria de Estado do Desenvolvimento Urbano - SEDU - Serviço Social autônomo Paranacidade;

Ortoimagem satélite IKonos, 2010 - abrangendo o perímetro urbano central de Paranaguá, com resolução espacial de 1 metro, cedida pela Secretaria Municipal de Urbanismo e Gestão Fundiária, Prefeitura Municipal de Paranaguá.

As fotografias aéreas e imagens de satélites foram mosaicadas usando 0 software Hugin. Esses mosaicos digitais foram georreferenciados no software Global Mapper e interpretados visualmente no software CartaLinx, com objetivo de delimitar as poligonais das classes de uso e cobertura da terra, de acordo com a classificação do Manual de Uso da Terra do IBGE (2006), adaptada para o perímetro urbano de Paranaguá.

\section{A CONFECÇÃO DE MAPAS PREDITIVOS}

Para a confecção dos mapas preditivos, utilizou-se a geração de modelos probabilísticos dinâmicos têmporo-espaciais, que modelam as previsões das mudanças do uso e cobertura da terra, gerados digitalmente por duas técnicas contíguas:

1‥ A modelagem temporal - pela a aplicação dos algoritmos da cadeia de Markov de $2^{a}$ ordem, que mostra como um sistema geográfico complexo evoluirá no tempo;

2a A modelagem espacial - por meio da aplicação da dinâmica dos Autômatos Celulares (CA), que mostram qual a forma, tamanho e direção que um 
A cartografia prospectiva e a geração de mapas preditivos do uso e cobertura da terra estudo de: caso perímetro urbano de Paranaguá

sistema geográfico complexo apresentará futuramente no espaço, em função da dinâmica imposta ou instalada sobre ele, em um dado momento.

Segundo Eastman (2006), uma execução típica das rotinas que geram as duas técnicas contíguas de modelagem, Markov e Ca_Markov, pode incluir milhares de operações de SIG, pois, principalmente na segunda rotina (Ca_Markov), envolve os processos de passagem de filtros booleanos e os cruzamentos dos dados Markovianos, obtidos na primeira rotina de Markov. Estas últimas operações são executada em passos, e por este motivo, ocupa intensivamente o computador, portanto isto acaba limitando outros usos do mesmo.

\section{A CADEIA DE MARKOV - COMO TÉCNICA DE MODELAR O USO E A COBERTURA DA TERRA NO TEMPO}

Os algoritmos da cadeia de Markov foram desenvolvidos pelo matemático russo Andrei Andreyevich Markov (1865 - 1922), como um modelo matemático particular de processo estocástico, que permite fazer uma previsão estimada do estado futuro de um sistema.

Conforme Eastman (2006), no software IDRISI - Andes 15.0, a técnica da modelagem presente como uma das rotinas é a da cadeia de Markov de $2^{a}$ ordem, que é um processo estocástico discreto, em um tempo discreto, que modela o uso e a cobertura da terra no tempo, onde o estado futuro $\left(t_{+1}\right)$ de um sistema, depende do estado do mesmo no tempo presente $\left(t_{0}\right)$ e do seu estado em um tempo passado $\left(t_{1}\right)$.

Para descrever a mudança do uso e cobertura da terra no tempo, de um período para outro, o processo markoviano de $2^{\mathrm{a}}$ ordem, calcula a probabilidade da mudança através da construção de uma matriz de probabilidades de transição, uma matriz de transição de áreas e um conjunto de mapas de probabilidade condicional, sendo estes confeccionados por meio dos cálculos das mudanças das variáveis mapeadas, que são as classes de uso e cobertura da terra em dois tempos sucessivos $\left(t_{1}\right.$ e $\left.t_{0}\right)$.

Para a cadeia de Markov de $2^{-a}$ ordem construir as matrizes de transição e os mapas de probabilidades para o estado futuro $\left(t_{+1}\right)$ de cada uma das classes de uso e cobertura da terra, faz-se necessário que se alimente o sistema com os dados de 
A cartografia prospectiva e a geração de mapas preditivos do uso e cobertura da terra estudo de: caso perímetro urbano de Paranaguá

dois mapas digitais, de dois períodos diferentes e sucessivos, que se sucedem cronologicamente $\left(t_{1}\right.$ e $\left.t_{0}\right)$, os quais devem apresentar mapeadas as mesmas classes de uso e cobertura da terra.

Assim, a Cadeia de Markov de $2^{\underline{a}}$ ordem desenvolve um processo markoviano, analisando as ocorrências da mudança do uso e cobertura da terra, de todas as categorias mapeadas, nos dois períodos distintos, presente e passado $\left(t_{0}\right.$ e $\left.t_{1}\right)$.

Com base nesta análise, o processo da cadeia de Markov infere pesos de 0 até 1 para a ocorrência de mudança do uso e da cobertura da terra em cada classe, nos dois períodos mapeados. Os resultados das análises da ocorrência de transição de uma classe em um tempo passado para um tempo presente servirão de base para projetar o uso e a cobertura da terra para um tempo futuro (EASTMAN, 2006; OLMEDO, 2008).

A análise probabilística markoviana é desencadeada automaticamente pelo software IDRISI, aplicando-se a rotina do módulo MARKOV sobre dois mapeamentos originais de datas consecutivas ( $t_{0}$ e $\left.t_{1}\right)$, cujo processo pode ser matematicamente demonstrado, como a probabilidade de transição de passo " $n$ ", conforme representado no quadro 01. (EASTMAN, 2006).

Quadro 01 - Cruzamento dos dados das categorias de transição das classes.

Fonte: EASTMAN, 2006, p. 185

\begin{tabular}{|c|c|c|c|c|}
\hline ESTADO & $\mathbf{0}$ & $\mathbf{1}$ & $\cdots$ & $\mathbf{M}$ \\
\hline $\mathbf{0}$ & $P_{00}^{(\mathrm{n})}$ & $P_{01}^{(\mathrm{n})}$ & $\ldots$ & $P_{0 \mathrm{M}}^{(\mathrm{n})}$ \\
\hline $\mathbf{1}$ & $P_{10}^{(\mathrm{n})}$ & $P_{11}^{(\mathrm{n})}$ & $\ldots$ & $P_{1 \mathrm{M}}^{(\mathrm{n})}$ \\
\hline$\ldots$ & $\cdots$ & $\cdots$ & $\ldots$ & $\cdots$ \\
\hline $\mathbf{M}$ & $P_{\mathrm{M} 0}^{(n)}$ & $P_{\mathrm{M} 1}^{(\mathrm{n})}$ & $\ldots$ & $P_{\mathrm{MM}}^{(n)}$ \\
\hline
\end{tabular}

Ou, equivalentemente representado por uma matriz " $P(n)$ ": 


$$
\mathrm{P}^{n}=\left[\begin{array}{ccccc}
\mathrm{P}_{00}^{(\mathrm{n})} \mathrm{P}_{01}^{(\mathrm{n})} & \ldots & \mathrm{P}_{0 \mathrm{M}}^{(\mathrm{n})} \\
\mathrm{P}_{10}^{(\mathrm{n})} & \mathrm{P}_{11}^{(\mathrm{n})} & \ldots & \mathrm{P}_{1 \mathrm{M}}^{(\mathrm{n})} \\
\ldots & \ldots & \ldots & \\
\mathrm{P}_{\mathrm{M} 0}^{(\mathrm{n})} & \mathrm{P}_{\mathrm{M} 1}^{(\mathrm{n})} & \ldots & & \mathrm{P}_{\mathrm{MM}}^{(\mathrm{n})}
\end{array}\right]
$$

Desta forma, segundo Eastman (2006) e Olmedo (2008), a aplicação da cadeia de Markov de $2^{a}$ ordem é uma série cronológica, que oferece como resultado uma matriz de probabilidade de transição entre todas as categorias, bem como uma matriz de transição de áreas, onde é indicado o número de pixels que podem passar por transformações, além de um conjunto de mapas ou imagens de probabilidade condicional $(0-1)$, para cada uma das categorias em um tempo $\left(t_{+1}\right)$ como uma projeção do tempo presente " $\mathrm{t}_{0}$ " e do tempo passado " $\mathrm{t}_{1}$ ", os quais serão utilizados na cadeia de Markov de $2^{\underline{a}}$ ordem, para projetar o uso e a cobertura da terra no tempo, ou seja, para um período de tempo futuro (Figura 02).

$\mathrm{Na}$ cadeia de Markov, as probabilidades de transição não mudam espacialmente com o tempo, o que caracteriza o processo markoviano como um processo estacionário no espaço. Assim, pode-se afirmar que este modelo estocástico da cadeia de Markov é deficitário, quando aplicado sozinho, para gerar um modelo futuro de mudança do uso e da cobertura da terra.

Portanto, pode-se dizer que o processo markoviano não tem conhecimento de dependência espacial, para modelar um sistema geográfico complexo, que se move espacialmente, pois este processo mostra apenas a probabilidade de mudança no tempo, de um estado local do uso e cobertura da terra, já que as probabilidades são arbitradas e não levam em conta critérios que englobem variáveis explicativas da dinâmica espacial de mudança (TENEDÓRIO, et. al., 2006). 
A cartografia prospectiva e a geração de mapas preditivos do uso e cobertura da terra estudo de: caso perímetro urbano de Paranaguá
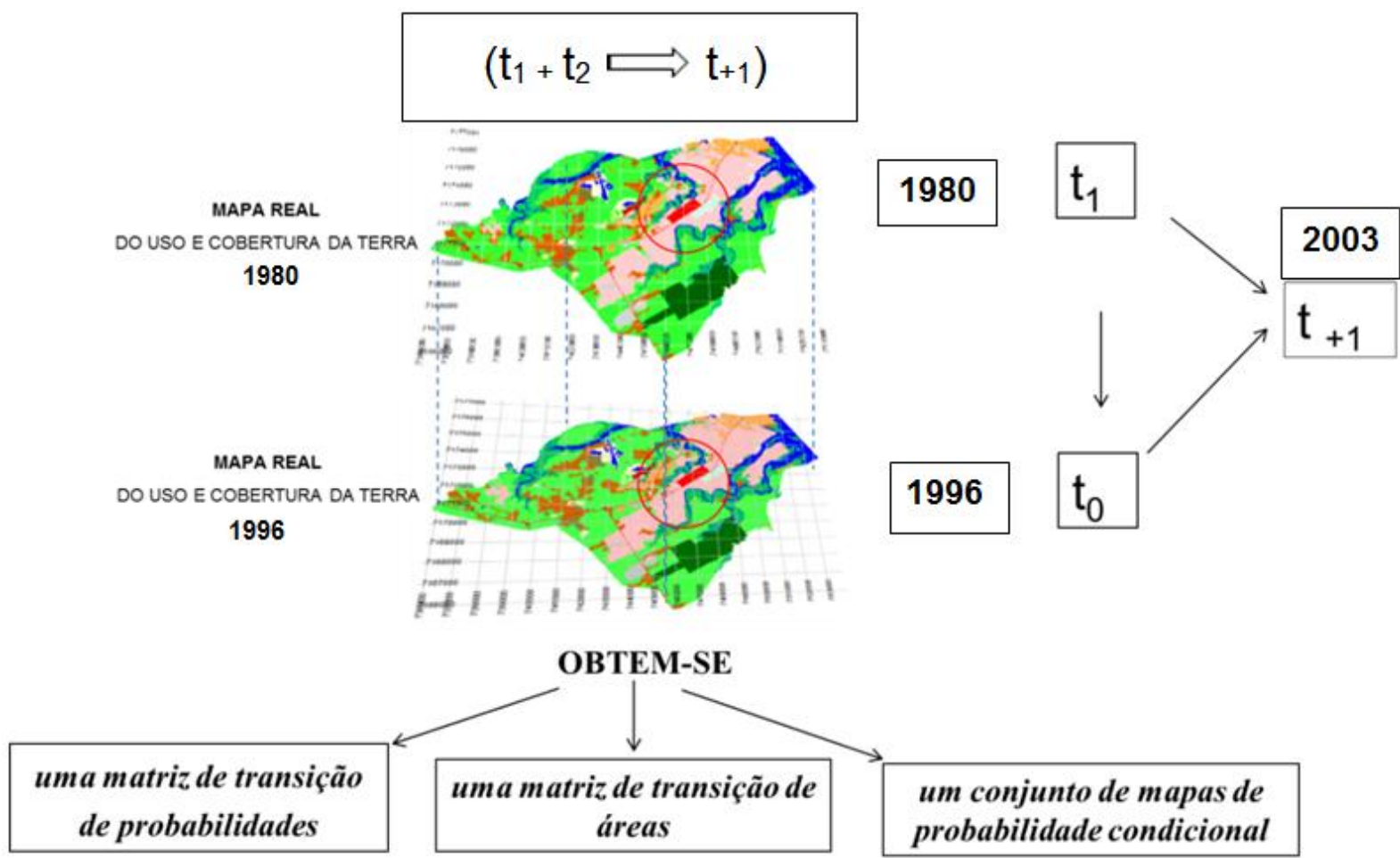

Figura 02: esquema do processo da cadeia de Markov de $2^{\mathrm{a}}$ ordem, a partir de dois mapas reais das classes de uso e cobertura da terra de duas datas contigua $\left(t_{1}\right.$ e $\left.t_{0}\right)$ para o perímetro urbano de Paranaguá.

Conforme exposto anteriormente, deduz-se que após aplicação da cadeia de Markov, deverão ser utilizados os Autômatos Celulares (CA) como técnica para modelar o espaço.

\section{OS AUTÔMATOS CELULARES (CA) - COMO TÉCNICA DE MODELAR O USO E A COBERTURA DA TERRA NO ESPAÇO.}

Os Autômatos Celulares (CA) foram criados por John von Newmann nos anos de 1950, com o objetivo de prover modelos formais para estudar processos de crescimento e dar uma prova matemática da possibilidade de auto reprodução de organismos biológicos (PÁDUA; VIEIRA, 2004).

Nos anos de 1970, o matemático John Holton Conway, criou como uma das aplicações dos Autômatos Celulares (CA), o game chamado "Jogo da Vida", o qual, baseando-se em regras simples, simula alterações em populações de seres vivos. Nesta aplicação de Autômato Celular, cada célula nasce ou morre de acordo com o 
A cartografia prospectiva e a geração de mapas preditivos do uso e cobertura da terra estudo de: caso perímetro urbano de Paranaguá

estado das células vizinhas e o jogo tende à morte de todas as células, ou a geração de padrões estáveis (CASTRO; CASTRO, 2008).

O uso de Autômatos Celulares (CA) também passou a ser utilizado como ferramenta para geração de modelos espaciais, nas ciências que usam o espaço como base para o seu entendimento, tais como a geografia, ecologia, biologia, hidrologia, meteorologia, dentre outras (ALMEIDA, et. al., 2010).

Em 1979 o geógrafo Waldo Tobler começou efetivamente explorar a aplicabilidade dos modelos de Autômatos Celulares (CA) em sistemas geográficos dinâmicos e complexos, quando em seu artigo "Cellular Geography", deste mesmo ano, propôs um modelo de espaço celular para o desenvolvimento da cidade de Detroit (TOBLER, W. 1979).

Para gerar modelos espaciais em ambiente computacional, o automatismo celular divide o território, ou espaço mapeado, em forma de uma malha digital, ou grade de agregação de células elementares, do tamanho de um pixel (Figura 03).

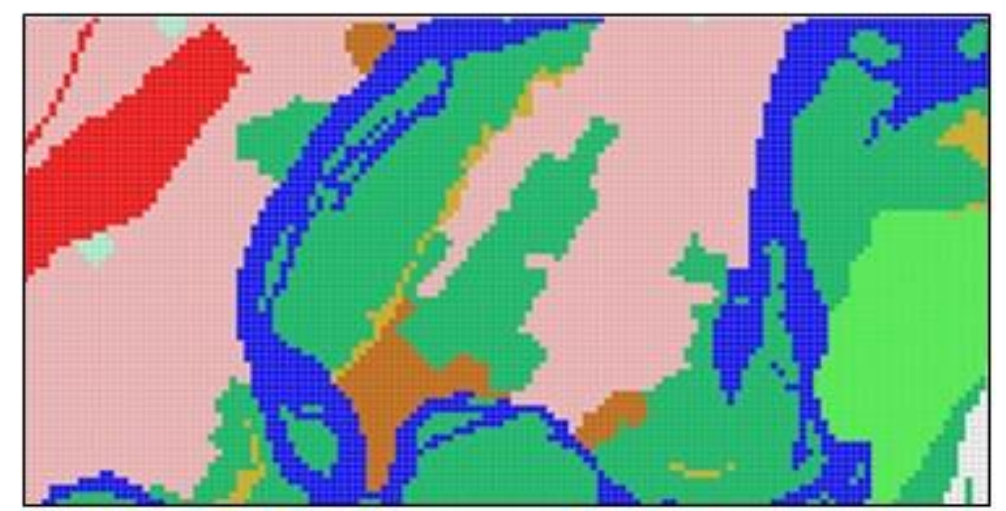

Figura 03: Representação de parte do território mapeado dividido em forma de uma grade uniforme composta por células do tamanho de um pixel

A dinâmica dos Autômatos Celulares (CA) passa a simular processos de mudança ou crescimento espacial de um sistema, baseando-se na premissa de que o estado futuro que uma célula irá assumir é o estado presente das suas células vizinhas.

No software IDRISI, a técnica da modelagem espacial através dos Autômatos Celulares (CA) é ativada pela rotina CA_Markov, a qual aplica um filtro 
booleano de grade média $5 \times 5$, sobre o mapa original da última data mapeada (Figura 04).

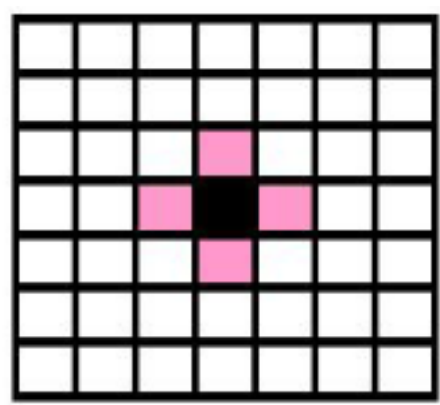

(a)

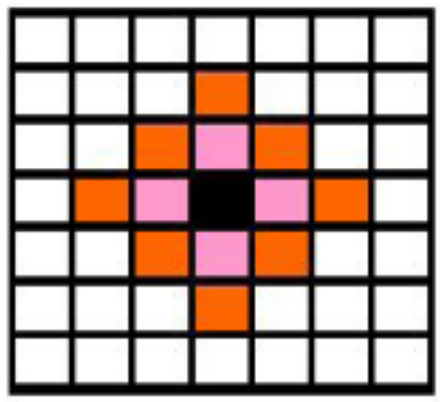

(b)

Figura 04: Filtro booleano que implementa a técnica da modelagem dos Autômatos Celulares (a) Filtro com a vizinhança $(5 \times 5)$ de von Neumann - os primeiros vizinhos; (b) - Filtro com a vizinhança (5x5) de von Neumann - apresentando os segundos vizinhos, o que passa a ser chamado de vizinhança estendida de von Newmann.

Fonte: GREMONINI, L. E VICENTINI, E, 2008.

As regras de vizinhança do filtro booleano $5 \times 5$, que faz rodar o processo dos Autômatos Celulares (CA), são as regras da chamada vizinhança estendida de von Newmann, que se apresentam com um array estendido até os segundos vizinhos (Figura 04).

A modelagem espacial dos Autômatos Celulares (CA) é implementada juntamente com aplicação das matrizes de transição e de áreas, assim como os mapas de probabilidades condicionais, produzidos quando da aplicação da cadeia de Markov de $2^{a}$ ordem. Por este motivo, a técnica da modelagem espacial através da aplicação de Autômatos Celulares (CA) deve ser consecutiva à aplicação da Cadeia de Markov de $2^{\text {a }}$ ordem (Figura 05).

A passagem do núcleo da grade do filtro booleano $5 \times 5$ sobre cada pixel do mapa da última data, irá implementar um fator de peso espacial entre os pixels vizinhos. O peso maior será atribuído para os pixels que representam uma área que mais se aproxima do uso e cobertura atual da terra do pixel em questão.

O resultado das medidas das células da vizinhança será comparado com os resultados das matrizes de transição e de área, sendo também multiplicado pelos mapas de probabilidade condicional, obtidos na fase da modelação temporal, através da aplicação da cadeia de Markov de $2^{\underline{a}}$ ordem. 
A cartografia prospectiva e a geração de mapas preditivos do uso e cobertura da terra estudo de: caso perímetro urbano de Paranaguá

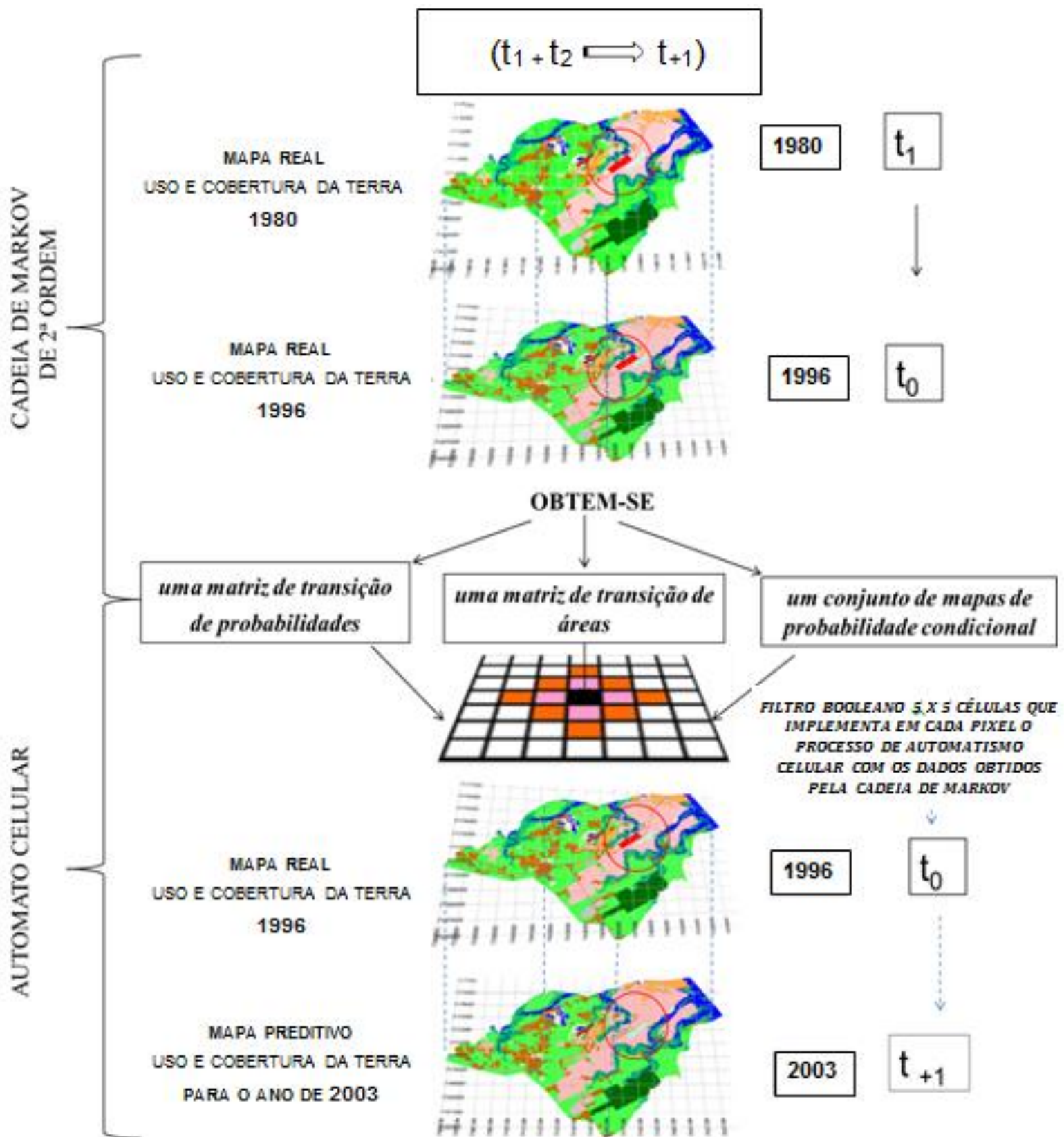

Figura 05: esquema do processo de modelação têmporo-espacial, implementada pela rotina CA_Markov do software Idrisi (observe que o processo completo envolve primeiramente a resolução da cadeia de Markov de $2^{2}$ ordem, cujos resultados vão implementar a passagem do filtro booleano 5 x 5 que estabelece as regras a serem utilizada para desenvolver o processo do Autômato Celular (CA) sobre cada pixel. Observa-se a mudança têmporo-espacial com maior nitidez na área circulada em vermelho.

Após a operação anterior, cada célula (pixel) "irá decidir" se obtém um resultado futuro integrando um caráter espacial, ou assumirá a probabilidade condicionada pelo entorno local. Este automatismo na análise irá assegurar que a 
A cartografia prospectiva e a geração de mapas preditivos do uso e cobertura da terra estudo de: caso perímetro urbano de Paranaguá

mudança no uso e cobertura da terra, para cada célula (pixel), ocorrerá o mais próximo da atualmente existente, e não totalmente aleatório (Figura 05).

A passagem do filtro booleano 5 × 5 , que implementará o automatismo celular (CA) sobre cada célula, fará com que esta passe a avaliar, o seu potencial de transição, para todos os usos e coberturas da terra mapeadas. Assim, cada classe mapeada poderá perder alguma área para uma ou mais classes, como também poderá ganhar áreas das outras classes.

Para resolver a competição entre as células vizinhas, ou para que a célula (pixel) em questão, sobre o qual está passando o filtro booleano, assuma os diferentes usos e coberturas da terra do seu entorno, é acionada automaticamente o filtro MOLA - Multi-Objetive land allocation que emprega uma técnica heurística de decisão.

O resultado desse processo interativo é que as mudanças da cobertura terrestre se desenvolvam como um processo de crescimento nas áreas de maior aptidão, próximas às áreas existentes.

\section{ETAPAS NO SOFTWARE IDRISI PARA A GERAÇÃO DOS MAPAS PREDITIVOS DO PERÍMETRO URBANO DE PARANAGUÁ}

Para gerar o modelo têmporo-espacial, em forma de mapa preditivo, da mudança do uso e cobertura da terra do perímetro urbano de Paranaguá, para um tempo futuro $\left(t_{+1}\right)$, aplicou-se primeiramente o processamento digital que contem a rotina do módulo da cadeia de Markov de $2^{\text {a }}$ ordem, através do procedimento "Gis Analysis- Change/Time Serial - Markov", do software IDRISI - Andes 15.0.

Nesta rotina foram utilizados como entrada, os mapas originais de uso e cobertura da terra, agrupados em pares de tempos sequenciais, conforme as datas que se sucedem e programados para gerarem um modelo de transição para um tempo futuro que se pré-determinou, da seguinte forma:

1. Mapas originais de 1980/1996 gerou o modelo de transição para 2003;

2. Mapas originais de 1996/2003 gerou o modelo de transição para 2006;

3. Mapas originais de 2003/2006 gerou o modelo de transição para 2009. 
A cartografia prospectiva e a geração de mapas preditivos do uso e cobertura da terra estudo de: caso perímetro urbano de Paranaguá

Assim, as combinações entre os mapas originais contíguos possibilitaram a geraração dos mapas preditivos, para as datas dos mapeamentos reais $(2003 ; 2006$ e 2009). Esta forma de geração serviu então, para determinar a precisão da utilização dos modelos estocásticos empregados e para a validação do processo, possibilitando comparações diretas entre os mapas gerados e os originais que se possuia.

Ao final de cada processamento da cadeia de Markov de $2^{a}$ ordem, para as datas anteriormente mencionadas, produziu-se uma matriz de probabilidade de transição, uma matriz de áreas de transição e uma série de imagens de probabilidades condicionais, a seguir descritas (Figura 02 e 05):

- Matriz de probabilidade de transição - é uma matriz que expressa a probabilidade de mudança de cada pixel de uma determinada classe de uso e cobertura da terra para qualquer outra classe no tempo (ou permanecer na mesma classe no período seguinte). Esta matriz é armazenada com um nome derivado da combinação do prefixo e da frase "transition_probabilities.txt";

- Matriz de áreas de transição - é uma matriz que indica a quantidade de pixels que podem passar por uma transformação, ou seja, expressa a área total (em células) que deverão mudar para outro tipo de uso e cobertura, no próximo período de tempo. Esta matriz é armazenada com o nome derivado da combinação do prefixo e da frase "transition_areas.txt".

- Uma série de imagens de probabilidades condicionais - obtida mediante a matriz de probabilidade de transição, onde a predição probabilística se materializa através da geração desta série de imagens (uma para cada categoria), para um tempo futuro $(t+1)$, onde o nível digital de cada pixel, expressa a probabilidade deste pixel passar a pertencer ou não a uma determinada categoria analisada. Estas imagens são armazenadas, uma para cada classe, com arquivo "Prob_class_(no da classe). rst".

As operações práticas para gerar um modelo temporal, com a rotina da cadeia de Markov de $2^{\text {a }}$ ordem, utilizando o módulo "Gis Analysis- Change/Time Serial - Markov", do software IDRISI - Andes 15.0, para cada par de mapas 
A cartografia prospectiva e a geração de mapas preditivos do uso e cobertura da terra estudo de: caso perímetro urbano de Paranaguá

originais de datas sucessivas, foram executadas, conforme 0 exemplo seguinte, onde se mostram os procedimentos de programação para a execução.

Nesta operação foram utilizados o cruzamento dos mapas originais das datas de 1980/1996, com objetivo de gerar um modelo de mudança do uso e cobertura da terra para o ano de 2003 (Figura 06).

Em primeiro lugar, abre-se o módulo no menu GIS Analysis e no submenu Change / Time Series - MARKOV, conforme mostrado na figura (Figura 06).

Este procedimento abre uma

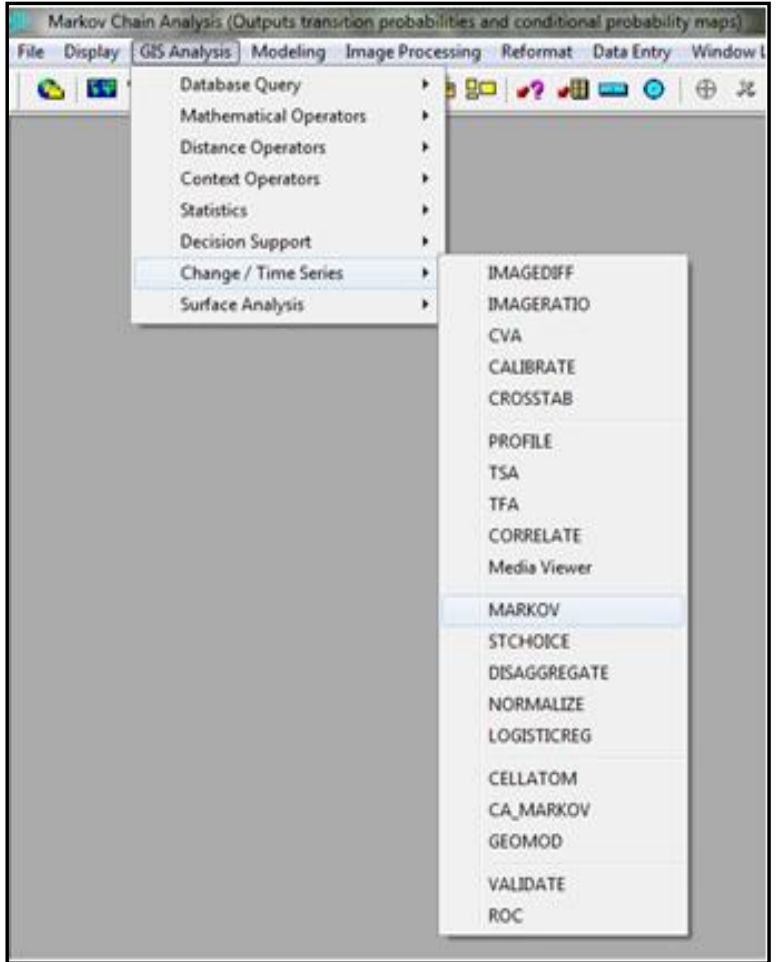

Figura 06: localização do menu gis analysis sub-menu change / time series módulo Markov.

nova janela, ou tela de entrada, onde se digita os dados ou nomes referentes aos arquivos de entrada e saída para se executar sobre os mesmos a rotina da cadeia de Markov de $2^{\text {a }}$ ordem (Figura 07).

$\mathrm{Na}$ janela mostrada na figura 07 , cada componente de entrada digitado representa:

- First (earlier) land cover image - neste quadro deve ser digitado o nome do arquivo que contém o primeiro mapa de uso e cobertura da terra, neste caso, o mapa original de uso e cobertura da terra de 1980;

- Second (later) land cover image - neste quadro deve ser digitado o nome do arquivo que contém o segundo mapa de uso e cobertura da terra. Aqui, o mapa original seria o de 1996;

- Prefix for output conditional probability images - neste local escreve-se o nome do arquivo de saída, que aqui foi nomeado como Prob_8096_2003; 
A cartografia prospectiva e a geração de mapas preditivos do uso e cobertura da terra estudo de: caso perímetro urbano de Paranaguá

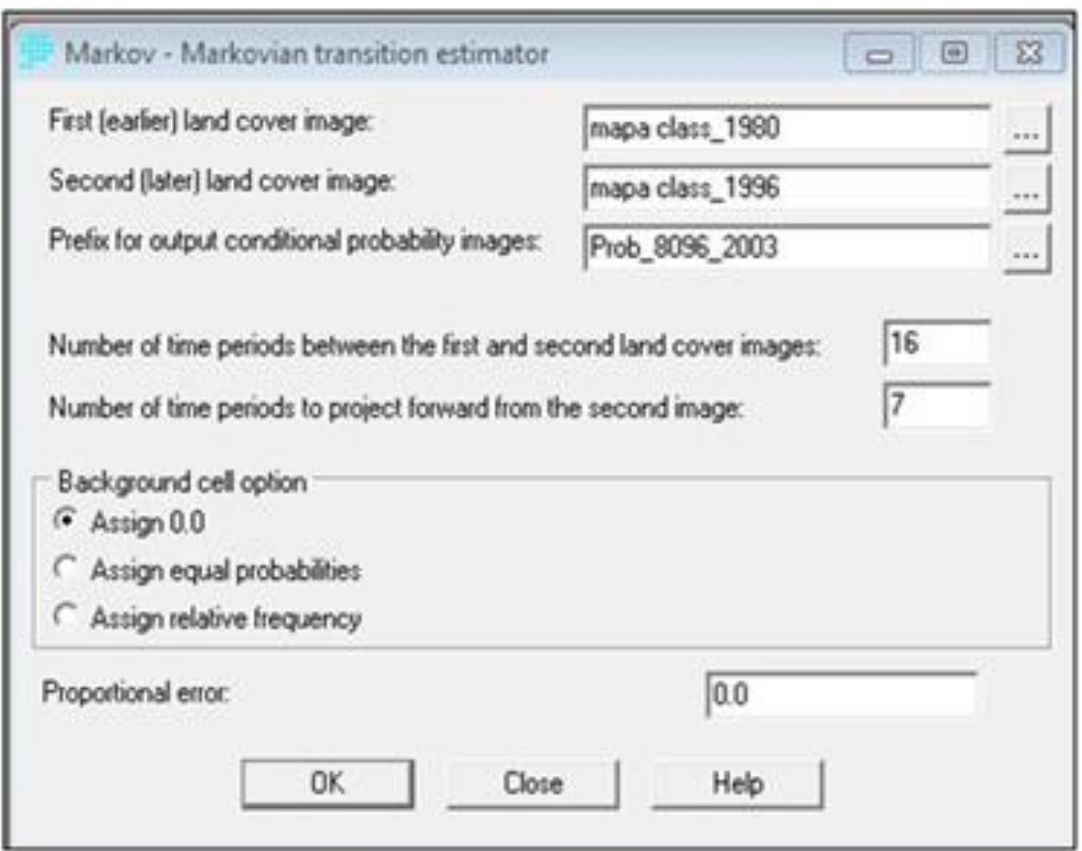

Figura 07: janela onde se escreve os dados de entrada e o nome de saída para a realização da rotina CA_Markov

- Number of time periods between the first and second land cover images - é o número de períodos (anos) entre o primeiro mapa e o segundo, que neste caso são 16 anos $(1996-1980=16)$;

- Number of time periods to Project forward from de second image neste quadro deve ser digitado o período que se pretende fazer a previsão, a partir da data do segundo mapa. Como o segundo mapa é do ano de 1996, e pretende-se fazer a previsão para 2003, este período de tempo é de 7 anos $(2003-1996=7)$.

- Back ground cell options - neste local, marca-se a primeira opção, Assing 0.0, como é recomendado no Tutorial do IDRISI Andes (EASTMAN, 2006);

- Proportional error - neste quadro digita-se o erro proporcional que se aceitará para esta análise. Segundo o Tutorial do IDRISI (2006), este valor seria de 0,15. Nesta rotina, optou-se por 0,0, para que não ocorresse nenhuma flutuação entre as análises, caso fossem refeitas.

Ao final do processamento, é obtida uma matriz de probabilidade de transição, uma matriz de áreas de transição e um conjunto de imagens de 
A cartografia prospectiva e a geração de mapas preditivos do uso e cobertura da terra estudo de: caso perímetro urbano de Paranaguá

probabilidade condicional (Figura 02), as quais posteriormente foram utilizadas no módulo CA_MARKOV, que completará o processamento da modelagem.

A segunda parte do processamento é a aplicação da rotina dos Autômatos Celulares (CA), que irá modelar a mudança espacial de cada classe mapeada. Este processamento é acionado pelo módulo no menu GIS Analysis e no sub-menu Change / Time Series - CA_MARKOV(Figura 08).

O procedimento anterior abre a

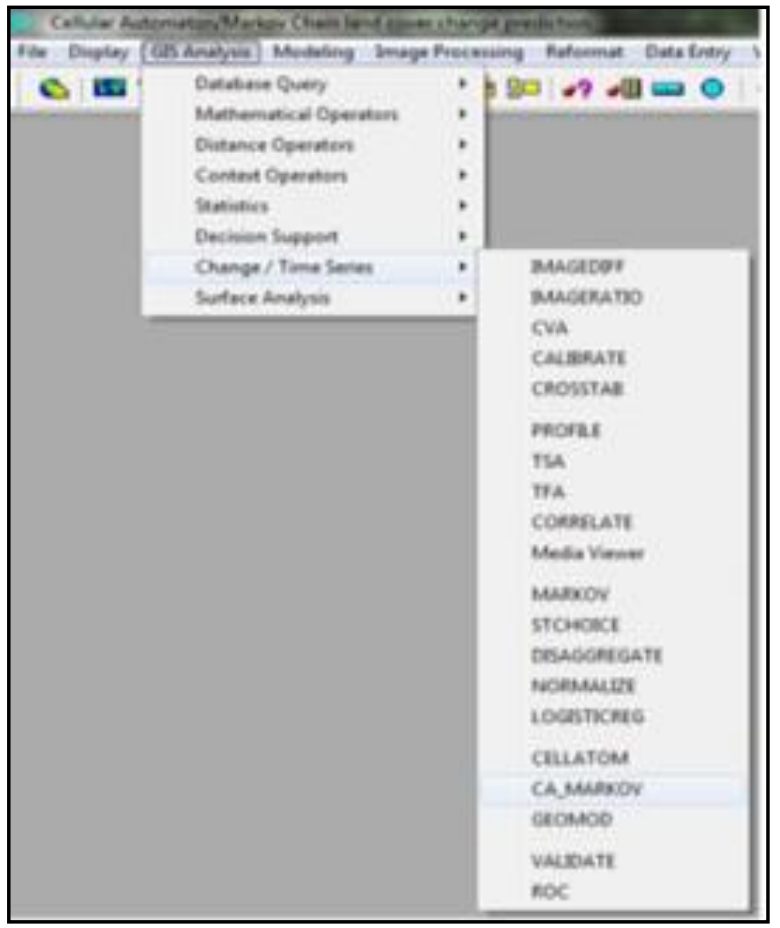
tela de entrada do módulo CA_MARKOV. Nesta janela, digitam-se os dados conforme solicitados (Figura 09).

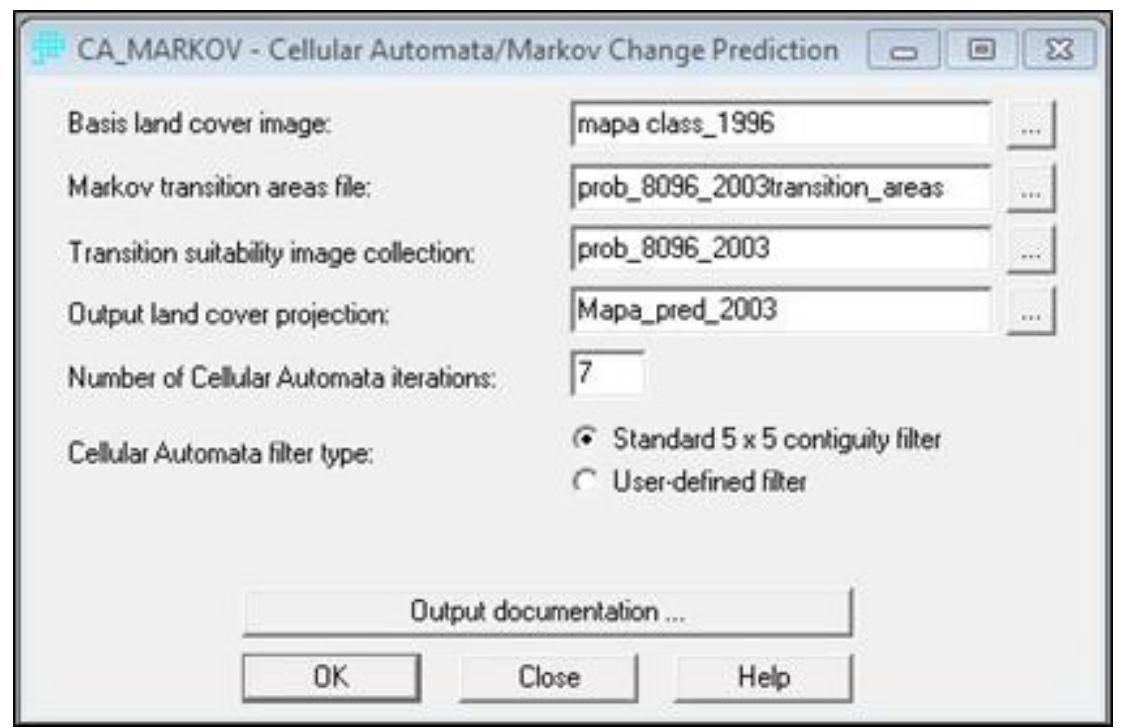

Figura 09: janela onde se escreve os dados de entrada e o nome de saída para a realização da rotina CA_Markov.

Os dados solicitados na janela mostrada na figura 09 são os seguintes:

- Basis land cover image - neste quadro deve ser digitado o nome do arquivo que contém o mapa usado como base para fazer a previsão - neste 
A cartografia prospectiva e a geração de mapas preditivos do uso e cobertura da terra estudo de: caso perímetro urbano de Paranaguá

caso é o mapa das classes de uso e cobertura da terra do último ano ( $\left.\mathrm{t}_{0}\right)$, ou seja, ano de 1996;

- Markov transition file - neste quadro chama-se a matriz de transição de áreas, gerada quando da aplicação da rotina da cadeia de Markov, sobre os pares de mapas (1980/1996), arquivada com o nome "prob_8096_2003transition_areas_probabilities.txt";

- Transition suitability image collection - neste quadro, chama-se o conjunto de imagens de probabilidade condicional, que também foi gerado quando da aplicação da rotina de Markov, arquivados com nome do prefixo estipulado "prob_8096_2003";

Output land cover projection - neste espaço se digita o nome que se quer dar ao resultado deste Módulo que vai aplicar a rotina CA-Markov,

"Mapa_pred_2003";

- Number of cellular automata iteration - neste quadro, digita-se o número de iterações que se deseja para fazer esta previsão. Neste caso, digitou-se 7, uma para cada ano, já que a previsão é para 7 anos;

- Cellular automata filter type - aqui se opta pelo filtro que se deseja utilizar para ativar a técnica dos Autômatos Celulares (CA) nessa previsão. Neste caso, foi selecionado o filtro booleano padrão, que é representado por uma grade de agregação $5 \times 5$, chamada de vizinhança estendida de von Newman.

Após a geração do mapa preditivo, Eastman (2006) indica que deve se passar pelo menos um filtro sobre o mesmo, para eliminar os ruídos aleatórios, em forma de pixels, dispersos sobre os mapas, como se tivesse espalhado sal e pimenta sobre o mesmo. Entre os filtros disponíveis pelo software IDRISI - Andes-15.0, é recomendado o uso da passagem de pelo menos um dos filtros, o Apdative Box, ou o filtro Mode.

Estes filtros são acionados pelo módulo no menu "Image Processing, submenu Enhancement / Filtre", o qual irá abrir uma nova janela, onde se escolherá o tipo e o tamanho do filtro que se deseja passar sobre o mapa preditivo. 
A cartografia prospectiva e a geração de mapas preditivos do uso e cobertura da terra estudo de: caso perímetro urbano de Paranaguá

Deve-se ter cuidado especial na passagem de filtros que apresentem grades muito grandes, do tipo $5 \times 5$ ou $7 \times 7$, pois estes podem substituir parte dos pixels da borda de uma classe por valores dos pixels de outra classe.

Após a passagem do filtro procedeu-se o cálculo das áreas abrangidas por cada classe de uso e cobertura da terra, aplicando-se sobre cada um dos mapas reais e preditivos a rotina "Gis Analysis - database Query - AREA", a qual produziu o valor das áreas ocupadas (em hectares - ha), por cada classe de uso e cobertura da terra, com objetivo de se construir uma tabela comparativa, entre as áreas das diferentes classes, dos mapas originais e os mapas preditivos.

Finalmente é aplicado o teste do índice Kappa $(\mathrm{K})$, para proceder a validação do processo estocástico de modelagem, têmporo-espacial para os mapeamentos preditivos de 2003, 2006 e 2009.

A aplicação do teste do índice Kappa (K) se faz necessário por este ser um coeficiente de avaliação estatística, que faz comparações nominais, para conhecer a proporção de concordância entre dois dados (real e preditivo), com objetivo de validar qualquer procedimento, depois que a concordância atribuída a casualidade é retirada de consideração.

A aplicação do teste do índice Kappa (K), foi realizada neste experimento através da aplicação da rotina "Gis Analysis - Database Query - CROSTAB", do software IDRISI - Andes 15.0, entrando-se com o mapeamento real como primeira imagem e o mapeamento preditivo como segunda imagem. Marca-se na janela a opção "Both cros-classification and tabulation", a qual gera uma matriz de erros, também conhecida como a matriz de confusão.

Para executar o teste Kappa $(\mathrm{K})$, esta rotina faz a comparação entre cada uma das classes do mapeamento real e do preditivo para todas as datas (2003; 2006 e 2009). A comparação é feita entre a quantidade de pixels existente em cada uma das classes do mapeamento preditivo, com a quantidade de pixels das mesmas classes e data do mapeamento real. A partir desta comparação, é gerada automaticamente uma matriz de erros, ou de confusão, onde são elencados os valores quantificados dos pixels coincidentes ou não, mostrando a acuracidade global das classes. 
A cartografia prospectiva e a geração de mapas preditivos do uso e cobertura da terra estudo de: caso perímetro urbano de Paranaguá

A maneira como os dados são apresentados na matriz de erro ou confusão, permite uma rápida visualização e localização dos erros e acertos de uma classificação de uso e cobertura da terra, em mapeamento preditivo, em relação à mesma classificação no mapeamento real.

Desta forma, tem-se um índice Kappa $(\mathrm{K})$ geral, para cada mapa preditivo de 2003, 2006 e 2009, e um índice Kappa (K) para cada classe de uso e cobertura da terra de cada ano, sendo este último calculado a partir da construção de uma matriz de tabulação cruzada.

A precisão quantificável pode variar de 0 (zero) a 1 (um), podendo cada classe preditiva, ser qualificada de acordo com a concordância com a classe real, desde péssima (0) até excelente (1), conforme o quadro 02.

Quadro 02 - Qualificação da concordância do índice Kappa (K)

Fonte: adaptado de Landis e Koch (1977)

\begin{tabular}{|c|c|}
\hline Índice Kappa & Desempenho \\
\hline$=0$ & Péssimo \\
\hline $0<\mathrm{k} \leq 0,2$ & Ruim \\
\hline $0,2<\mathrm{k} \leq 0,4$ & Razoável \\
\hline $0,4<\mathrm{k} \leq 0,6$ & Bom \\
\hline $0,6<\mathrm{k} \leq 0,8$ & Muito Bom \\
\hline $0,8<\mathrm{k} \leq 1,0$ & Excelente \\
\hline
\end{tabular}

\section{RESULTADOS E DISCUSSÕES}

As fotografias aéreas $e$ imagens de satélites mosaicadas e georreferenciadas resultaram nos mapas reais das classes de uso e cobertura da terra para os anos de: 1980, 1996, 2003, 2006 e 2009 (Figura 10).

A partir dos cruzamentos dos mapeamentos reais, ou originais, foram gerados os modelos probabilísticos dinâmicos têmporo-espaciais, em forma de mapas preditivos, para o ano de 2003, (cruzamento dos mapas reais de 1980/1996); 2006 (cruzamento dos mapas reais de 1996/2003) e para 2009 (cruzamento dos mapas reais de 2003/2006). 
A cartografia prospectiva e a geração de mapas preditivos do uso e cobertura da terra estudo de: caso perímetro urbano de Paranaguá

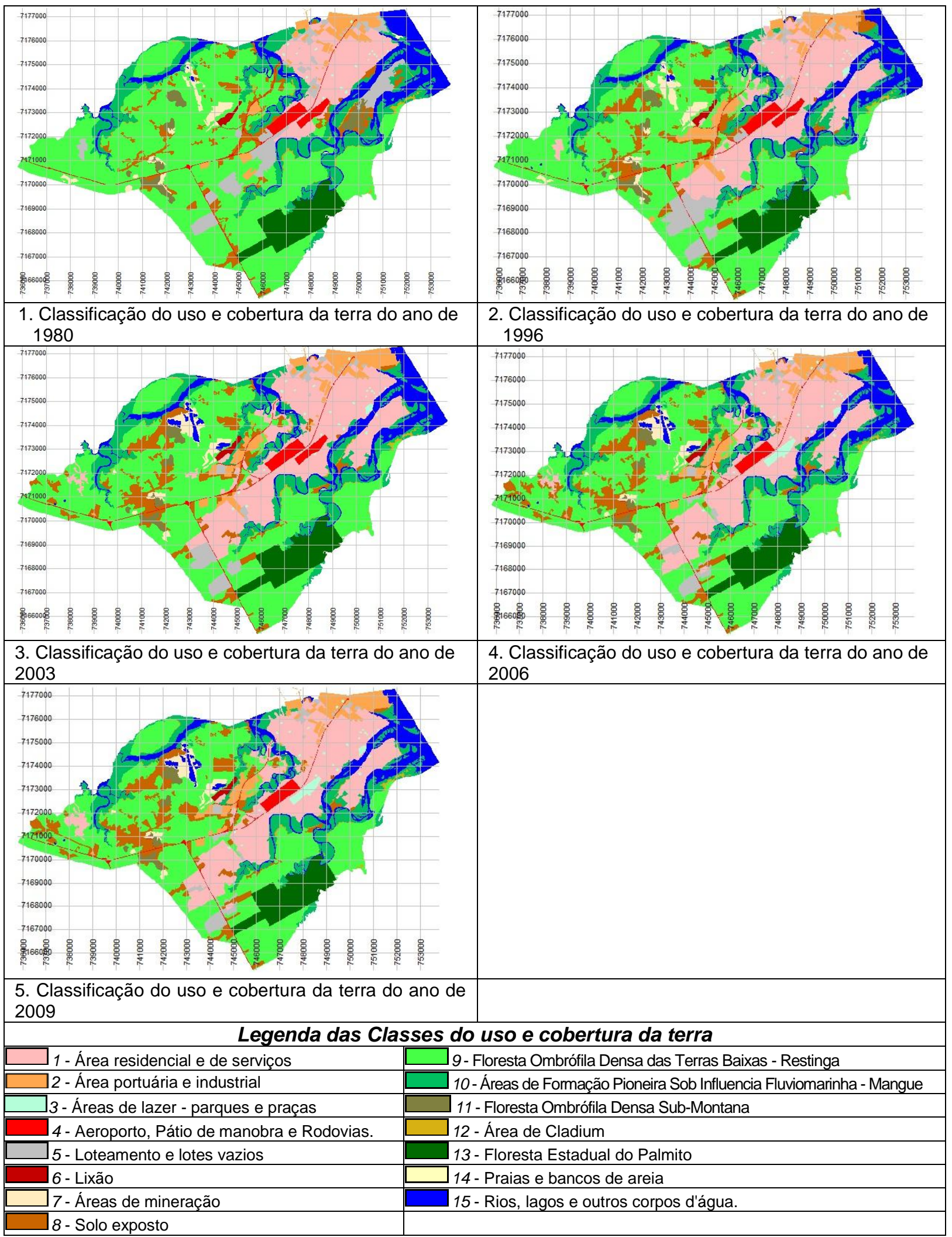

Figura 10: mapas originais de uso e cobertura da terra do perímetro urbano de Paranaguá dos anos 1980, 1996, 2003, 2006 e 2009. 
A cartografia prospectiva e a geração de mapas preditivos do uso e cobertura da terra estudo de: caso perímetro urbano de Paranaguá

A geração dos mapas preditivos, para as datas de 2003, 2006 e 2009, foi realizada em função dos mapeamentos reais que se tinha para estas datas, e para se determinar a precisão da utilização desta modelagem, através da comparação entre os mapas preditivos e os mapeamentos reais (Figura 12).

Nos mapas preditivos, resultantes deste processamento estocástico, ocorreram ruídos de fundo denominados de "sal e pimenta", o que é considerado como um fato normal (EASTMAN, 2006). Para a sua eliminação foram passados diversos tamanhos de grades de filtros. Comparando-se a passagem destes filtros, com grades de diversos tamanhos, sobre todos os mapeamentos preditivos, constatou-se que os melhores resultados visuais de limpeza do ruído aleatório, causadores do efeito "sal e pimenta", foram alcançados nos mapeamentos preditivos, onde foi utilizado o filtro Adaptive Box com grades do tamanho de $7 \times 7$ (Figura 11).

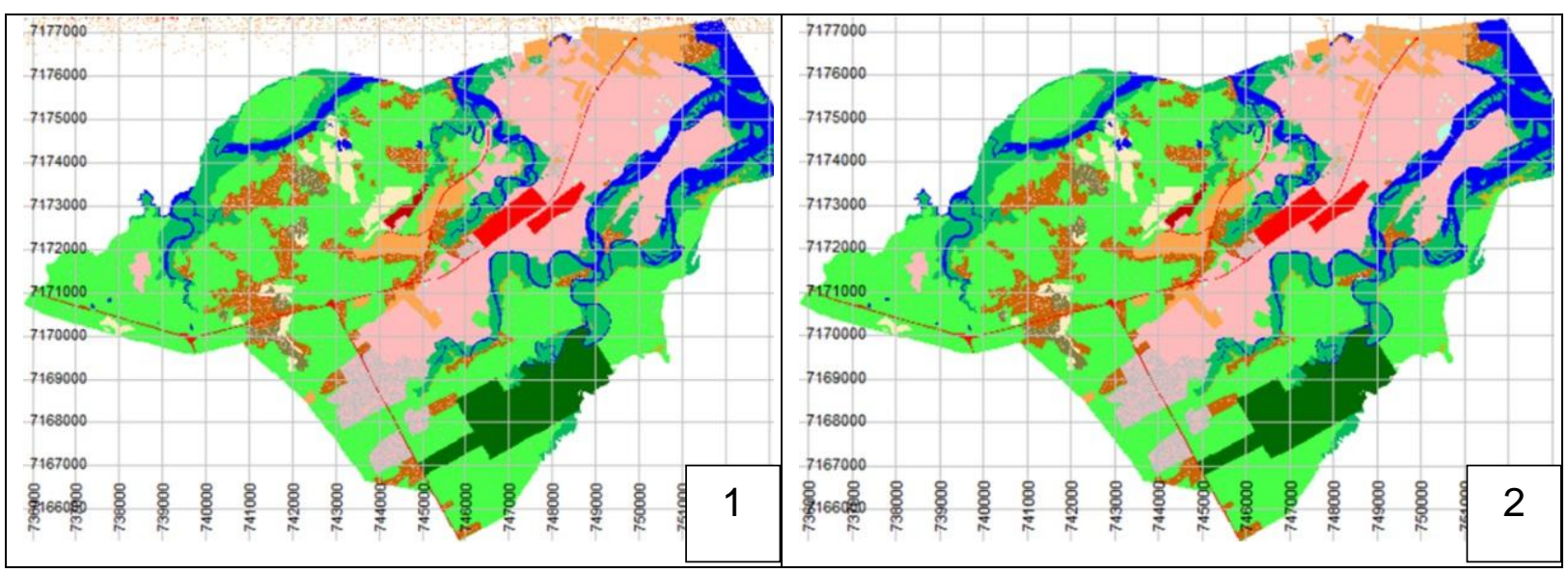

Figura 11: efeito da passagem de filtro sobre o mapa preditivo, para eliminar o ruído aleatório, em forma de pixels pretos e brancos, ou ainda colorido, disperso sobre os mapas, como se tivesse espalhado sal e pimenta sobre o mesmo. Mapa (1) sem a passagem de filtro. Mapa (2) após ter passado uma vez o filtro Adative Box 7 × 7 .

Após a passagem dos vários tamanhos de filtros, procedeu-se às comparações entre os mapas preditivos e os mapas originais, escolhendo-se para isto os mapas preditivos, onde se passou o filtro Adaptive Box $7 \times 7$, o qual visualmente havia mostrado os melhores resultados na filtragem do ruído aleatório, melhor observado na escala aqui apresentada, na borda superior do mapeamento (Figura 11). 
A cartografia prospectiva e a geração de mapas preditivos do uso e cobertura da terra estudo de: caso perímetro urbano de Paranaguá

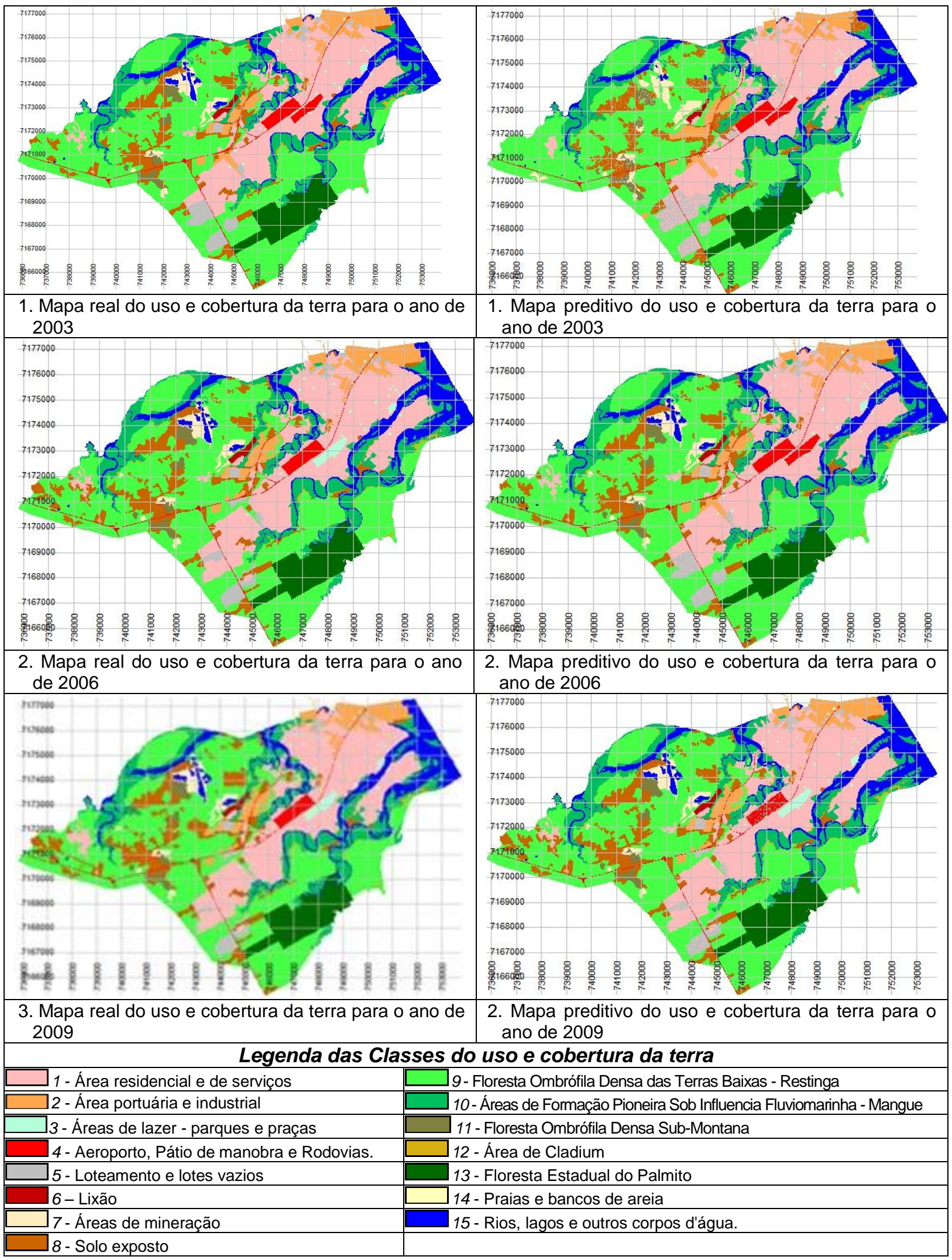

Figura 12: comparações, entre os mapas reais e os mapas preditivos de 2003, 2006 e 2009, das classes de uso e cobertura da terra do perímetro urbano de Paranaguá. 
A primeira avaliação foi obtida através da comparação das áreas de cada uma das classes de uso e cobertura da terra, entre os mapas originais e os mapas preditivos, para as datas de 2003, 2006 e 2009 (Figura 12; Quadro 03).

Quadro 03 - Comparação entre as áreas das classes de uso e cobertura da terra, dos mapas reais e preditivos do perímetro urbano de Paranaguá, para os anos de 2003, 2006, 2009.

\begin{tabular}{|c|r|r||r|r|r||r|r|r|r|}
\hline Classes & $\begin{array}{c}\text { Área real } \\
\mathbf{2 0 0 3}\end{array}$ & $\begin{array}{c}\text { Área } \\
\text { prevista } \\
2003\end{array}$ & $\begin{array}{c}\text { Percentual } \\
\text { de } \\
\text { aproximação }\end{array}$ & $\begin{array}{c}\text { Área real } \\
\text { em 2006 }\end{array}$ & $\begin{array}{c}\text { Área } \\
\text { prevista } \\
2006\end{array}$ & $\begin{array}{c}\text { Percentual } \\
\text { de } \\
\text { aproximação }\end{array}$ & $\begin{array}{c}\text { Área real } \\
\text { em 2009 }\end{array}$ & $\begin{array}{c}\text { Área } \\
\text { prevista } \\
2009\end{array}$ & $\begin{array}{c}\text { Percentual } \\
\text { de } \\
\text { aproximação }\end{array}$ \\
\hline Classe 1 & $\mathbf{2 . 1 0 9 , 9 8}$ & $2.092,88$ & 99,19 & $\mathbf{2 . 1 8 3 , 4 5}$ & $2.178,34$ & 99,77 & $\mathbf{2 . 2 1 4 , 1 9}$ & $2.222,17$ & 100,36 \\
\hline Classe 2 & $\mathbf{4 5 6 , 3 2}$ & 436,26 & 95,60 & $\mathbf{4 6 1 , 9 3}$ & 445,81 & 96,51 & $\mathbf{4 7 1 , 4 7}$ & 457,81 & 97,10 \\
\hline Classe 3 & $\mathbf{3 1 , 4 6}$ & 29,60 & 94,11 & $\mathbf{7 9 , 8 4}$ & 31,29 & 39,19 & $\mathbf{8 1 , 9 1}$ & 89,96 & 109,83 \\
\hline Classe 4 & $\mathbf{2 1 2 , 1 7}$ & 212,92 & 100,35 & $\mathbf{1 6 2 , 6 5}$ & 212,44 & 130,62 & $\mathbf{1 6 2 , 6 4}$ & 143,79 & 88,41 \\
\hline Classe 5 & $\mathbf{2 4 4 , 6 6}$ & 308,59 & 126,13 & $\mathbf{1 9 9 , 7 3}$ & 220,92 & 110,61 & $\mathbf{1 7 2 , 9 4}$ & 178,03 & 102,94 \\
\hline Classe 6 & $\mathbf{3 0 , 3 6}$ & 25,18 & 82,95 & $\mathbf{3 0 , 3 6}$ & 29,78 & 98,10 & $\mathbf{3 0 , 3 6}$ & 30,36 & 100,01 \\
\hline Classe 7 & $\mathbf{1 5 1 , 6 7}$ & 201,90 & 133,12 & $\mathbf{1 5 1 , 4 0}$ & 152,45 & 100,69 & $\mathbf{1 5 2 , 1 6}$ & 148,06 & 97,31 \\
\hline Classe 8 & $\mathbf{7 7 2 , 4 3}$ & $\mathbf{7 3 7 , 2 4}$ & 95,44 & $\mathbf{8 3 2 , 2 2}$ & 827,71 & 99,46 & $\mathbf{9 0 5 , 1 9}$ & 904,71 & 99,95 \\
\hline Classe 9 & $\mathbf{4 . 0 1 3 , 8 9}$ & $4.031,38$ & 100,44 & $\mathbf{3 . 9 2 6 , 3 8}$ & $3.943,38$ & 100,43 & $\mathbf{3 . 8 3 2 , 8 0}$ & $3.855,33$ & 100,59 \\
\hline Classe 10 & $\mathbf{1 . 4 0 9 , 8 6}$ & $1.410,63$ & 100,05 & $\mathbf{1 . 4 0 1 , 4 0}$ & $1.387,56$ & 99,01 & $\mathbf{1 . 4 0 4 , 4 4}$ & $1.395,30$ & 99,35 \\
\hline Classe 11 & $\mathbf{1 0 8 , 5 5}$ & 102,31 & 94,25 & $\mathbf{1 0 8 , 5 4}$ & 105,23 & 96,95 & $\mathbf{1 0 8 , 5 4}$ & 108,56 & 100,02 \\
\hline Classe 12 & $\mathbf{7 5 , 8 0}$ & 75,72 & 99,89 & $\mathbf{7 5 , 8 0}$ & 75,60 & 99,74 & $\mathbf{7 5 , 8 0}$ & 75,59 & 99,73 \\
\hline Classe 13 & $\mathbf{5 3 3 , 4 7}$ & 532,81 & 99,88 & $\mathbf{5 3 3 , 4 7}$ & 533,47 & 100,00 & $\mathbf{5 3 3 , 4 7}$ & 533,49 & 100,01 \\
\hline Classe 14 & $\mathbf{2 , 5 3}$ & 1,49 & $\mathbf{5 8 , 8 8}$ & $\mathbf{2 , 5 3}$ & 2,51 & 99,21 & $\mathbf{2 , 5 3}$ & 2,51 & 99,21 \\
\hline Classe 15 & $\mathbf{9 3 4 , 7 0}$ & 884,48 & $\mathbf{9 4 , 6 3}$ & $\mathbf{9 3 8 , 1 5}$ & 941,36 & 100,34 & $\mathbf{9 3 9 , 4 0}$ & 942,02 & 100,28 \\
\hline Total & $\mathbf{1 1 . 0 8 7 , 8 4}$ & $\mathbf{1 1 . 0 8 3 , 4 1}$ & 99,96 & $\mathbf{1 1 . 0 8 7 , 8 4}$ & $\mathbf{1 1 . 0 8 7 , 8 8}$ & 100,00 & $\mathbf{1 1 . 0 8 7 , 8 5}$ & $\mathbf{1 1 . 0 8 7 , 7 0}$ & 100,00 \\
\hline
\end{tabular}

Nota: Os valores expressos em vermelho são os resultados das áreas das classes preditivas, dos três mapeamentos, que mais se aproximaram do valor da área real da mesma classe, ou seja, entre o percentual de acerto de $99,5 \%$ a $100,5 \%$.

Ao visualizar os valores das áreas das classes dos mapeamentos do uso e cobertura da terra, para os diferentes anos, constatou-se que a maior quantidade de resultados com aproximações entre as áreas das classes dos mapas preditivos e as reais ocorreu no mapeamento preditivo de 2009.

O mapeamento preditivo do uso e cobertura da terra, do ano de 2003 comparado com o mapeamento real da mesma data, apresentou 5 classes $(4,9,10$, 12 e 13), com o maior índice de aproximação entre as áreas preditivas e as reais de todos os anos. Também se constatou que a pior aproximação ocorreu com a classe 14 e a melhor aproximação se deu na classe 10. As classes 4, 5, 7, 9 e 10 apresentaram áreas maiores que as reais, sendo que as maiores discrepâncias foram verificadas nas classes 5 e 7.

No tocante ao mapa preditivo de 2006, constatou-se que o mesmo apresentou 5 classes (1, 9, 12, 13 e 15), com o maior índice de aproximação entre 
A cartografia prospectiva e a geração de mapas preditivos do uso e cobertura da terra estudo de: caso perímetro urbano de Paranaguá

as áreas preditivas e as reais de todos os anos. A maior aproximação ocorreu na classe 13. As classes 4, 5, 7, 9, 13 e 15 do mapeamento preditivo apresentaram áreas maiores que as reais.

Neste mapeamento preditivo de 2006, nota-se que a maior discrepância entre uma classe preditiva e a original ocorreu na classe 3 - Áreas de lazer - parques e praças e na classe 4 - Aeroporto, Pátio de manobra e Rodovias em função da intervenção de políticas públicas municipais, que transformaram a área do aeroporto do municipio (classe 4) em áreas de lazer (classe 3).

$\mathrm{Na}$ comparação das áreas das classes do mapeamento preditivo de 2009, com o mapeamento real da mesma data, constataram-se 7 classes $(1,6,8,11,12$, 13 e 15) que apresentaram maior índice de aproximação entre as áreas preditivas e as reais em relação a todos os anos. As classes 3, 5, 6, 9, 11, e 15, do mapeamento preditivo apresentaram áreas maiores que as reais, mas não apresentaram uma discrepância significativa que possa chamar a atenção entre as áreas preditivas e reais.

Finalmente foi executada a validação do processo estocástico de modelagem, têmporo-espacial para os mapeamentos preditivos de 2003, 2006 e 2009, através da aplicação do teste do índice Kappa (K).

Os resultados desta aplicação foram obtidos pelo processo de cruzamento entre a quantidade de pixels existente, em cada uma das classes do mapeamento preditivo, comparados com a quantidade de pixels das mesmas classes e data do mapeamento real. Este cruzamento produziu uma matriz de erros, ou de confusão, onde foram elencados os valores quantificados dos pixels dos mapeamentos preditivos, coincidentes ou não com os dos mapeamentos reais.

Com os valores anteriormente descritos, procedeu-se à montagem de quadros comparativos das diversas classes, para os anos em questão, utilizando-se da aplicação da relação de concordância, adaptada da proposta de Landis e Koch (1977), para avaliar a qualificação de coincidência das classes dos mapeamentos preditivos, com as classes do mapeamento real (Quadro 4).

Ao analisar o resultado do quadro de comparação da qualidade de concordância do índice Kappa $(K)$, pôde-se constatar que todos os mapeamentos 
A cartografia prospectiva e a geração de mapas preditivos do uso e cobertura da terra estudo de: caso perímetro urbano de Paranaguá

preditivos $(2003,2006,2009)$ apresentaram excelente qualidade de concordância com o real, variando de 0,9245 para o mapeamento preditivo de 2003 até 0,9781, para o mapeamento preditivo de 2009.

Quadro 4 - Qualidade da concordância do índice Kappa das classes do mapeamento preditivo e do índice geral dos mapeamentos preditivos de2003, 2006 e 2009.

\begin{tabular}{|c|c|c|c|c|c|c|c|c|c|c|c|}
\hline & \multicolumn{3}{|c|}{\begin{tabular}{|c|} 
Concordância de Kappa $(\mathrm{K})$ \\
para o mapeamento de 2003
\end{tabular}} & \multicolumn{4}{|c|}{$\begin{array}{c}\text { Concordância de Kappa(K) para o } \\
\text { mapeamento de } 2006\end{array}$} & \multicolumn{4}{|c|}{$\begin{array}{l}\text { Concordância de Kappa(K) para o } \\
\text { mapeamento de } 2009\end{array}$} \\
\hline & $\begin{array}{l}\text { Excelente } \\
0,8-1,0\end{array}$ & $\begin{array}{c}\text { Muito Boa } \\
0,6-0,8\end{array}$ & $\begin{array}{c}\text { Boa } \\
0,4-0,6\end{array}$ & $\begin{array}{c}\text { Excelente } 0,8 \\
-1,0\end{array}$ & $\begin{array}{c}\text { Muito Boa } \\
0,6-0,8\end{array}$ & $\begin{array}{c}\text { Boa } \\
0,4-0,6\end{array}$ & \begin{tabular}{|l|} 
Razoável \\
$0,2-0,4$
\end{tabular} & $\begin{array}{c}\text { Excelente } \\
0,8-1,0\end{array}$ & \begin{tabular}{|c|} 
Muito Boa \\
$0,6-0,8$
\end{tabular} & $\begin{array}{c}\text { Boa } \\
0,4-0,6\end{array}$ & $\begin{array}{l}\text { Razoável } \\
0,2-0,4\end{array}$ \\
\hline Classe 1 & 0,9999 & & & 0,9609 & & & & 0,9706 & & & \\
\hline Classe 2 & 0,8704 & & & 0,8881 & & & & 0,9556 & & & \\
\hline Classe 3 & 0,8224 & & & & & & 0,3650 & 0,9094 & & & \\
\hline Classe 4. & 0,9405 & & & & & 0,629 & & 0,8819 & & & \\
\hline Classe 5 & 0,9997 & & & & 0,799 & & & 0,8647 & & & \\
\hline Classe 6 & & & 0,5215 & 0,9805 & & & & 0,9999 & & & \\
\hline Classe 7 & & 0,763 & & 0,9187 & & & & 0,9676 & & & \\
\hline Classe 8 & & 0,690 & & 0,8725 & & & & 0,8733 & & & \\
\hline Classe 9 & & 0,630 & & 0,9694 & & & & 0,9755 & & & \\
\hline Classe 10 & 0,9234 & & & 0,9830 & & & & 0,9896 & & & \\
\hline Classe 11 & 0,9628 & & & 0,9691 & & & & 0,9998 & & & \\
\hline Classe 12 & 0,8237 & & & 0,9922 & & & & 0,9922 & & & \\
\hline Classe 13 & 0,9917 & & & 0,9999 & & & & 0,9999 & & & \\
\hline Classe 14 & 0,9985 & & & 0,9907 & & & & 0,9907 & & & \\
\hline Classe 15 & & & 0,5867 & 0,9952 & & & & 0,9976 & & & \\
\hline $\begin{array}{l}\text { KAPPA } \\
\text { GERAL }\end{array}$ & 0,9245 & & & 0,9691 & & & & 0,9781 & & & \\
\hline
\end{tabular}

Para o ano de 2003, observa-se que duas classes (6 e 15) apresentaram apenas boa qualidade de concordância. Três classes $(7,8,9)$, foram classificadas com qualidade de concordância muito boa, e dez classes apresentaram excelente qualidade de concordância.

Para o ano de 2006, constata-se que a classe 3 apresentou uma precisão de qualificação apenas razoável. Este fato pode ser explicado pela intervenção do poder público, que transformou a área do aeroporto do município, classificado anteriormente na classe 4, para uma área de lazer, classe 3.

Neste mesmo ano, a classe 5 - Loteamento e lotes vazios - apareceu com uma concordância muito boa, pois, na projeção estocástica do modelo em forma de mapeamento preditivo, deveria haver um crescimento linear do estoque de lotes vazios, fato que não ocorreu, pela falta de incentivo do poder público. Mesmo com 
A cartografia prospectiva e a geração de mapas preditivos do uso e cobertura da terra estudo de: caso perímetro urbano de Paranaguá

os problemas anteriormente apontados, para esse ano de 2006, apresentou um índice excelente de qualificação da concordância em 12 classes.

Para o ano de 2009, foi verificado que as 15 classes de uso e cobertura da terra apresentaram índices excelentes de qualificação da concordância. Esse fato pode ser justificado pela utilização de mapeamentos reais muito próximos (3 anos de diferença), e pela projeção estocástica também ser muito próxima do último mapeamento real (3 anos).

\section{CONCLUSÕES}

Essa pesquisa mostrou que os mapeamentos preditivos, como produto da cartografia prospectiva, baseada na geração de modelos dinâmicos têmporoespaciais, da mudança do uso e cobertura da terra, são ferramentas, que possibilitam analisar e projetar tendências, para sistemas geográficos complexos, onde intervêm muitos elementos.

Os modelos dinâmicos têmporo-espaciais, em forma de mapas preditivos, gerados pelo módulo CA-Markov do software IDRISI - Andes 15.0, se mostraram como uma feramenta possível e apropriada para ser utilizada como uma projeção de tendências espaciais de crescimento e de direcionamento, que podem apresentar as classes de uso e cobertura da terra. Ressalta-se que seus resultados sejam analisados com cautela, e as tendências dos processos de organização espacial, seja interpretada adentro do conhecimento geográfico de cada área, onde:

- este tipo de modelo gerado pela combinação das rotinas da cadeia de Markov de $2^{a}$ ordem, juntamente com Autômatos Celulares (CA), não prevê apenas a evolução do uso da terra no tempo, mas também mostra o seu crescimento e direcionamento no espaço;

- os resultados dos modelos dinâmicos têmporo-espaciais, realizados pela aplicação do módulo CA-Markov (combinação das rotinas da cadeia de Markov e Autômatos Celulares - CA), produzem um prognóstico da organização espacial em forma de mapas preditivos, que formam a base da Cartografia Prospectiva;

- os modelos dinâmicos têmporo-espaciais, refletem as tendências de mudança, crescimento e direcionamento, que estão presentes em tempos 
A cartografia prospectiva e a geração de mapas preditivos do uso e cobertura da terra estudo de: caso perímetro urbano de Paranaguá

anteriores, que se sucedem cronologicamente $\left(t_{1}\right.$ e $\left.t_{0}\right)$, tomados como base para a geração do modelo preditivo;

- Os modelos preditivos não tem o poder de prever as mudanças bruscas, no acréscimo ou decréscimo de áreas de uma classe de uso ou cobertura da terra, quando ocorrerem intervenções severas do poder público ou privado, ou de políticas públicas, que transformam áreas, classificadas como pertencentes a uma classe em outra classe, como por exemplo, ocorrido em 2006 em Paranaguá, quando da transformação repentina da área do aeroporto em um parque urbano.

- O modelo dinâmico têmporo-espacial, de mudança do uso e cobertura da terra, é sensível a mudanças bruscas na organização espacial, passa a ser melhor indicado para acompanhar e prever a evolução das áreas ou classes da paisagem, quando não houver uma interferência direta e agressiva do poder público ou privado na transformação da paisagem.

Por outro lado, os testes aplicados nesta pesquisa, sobre os modelos dinâmicos têmporo-espaciais (mapas preditivos), mostraram parâmetros de predição confiáveis quando foram aplicadas avaliações por comparações dos tamanhos das áreas, entre as classes preditivas e as reais, de uso e cobertura da terra, além de apresentarem resultados excelentes na validação da qualidade de concordância, quando aplicado o teste do índice Kappa (K).

Os parâmetros anteriores se traduzem em segurança para indicar a aplicação destas técnicas de geração de modelos têmporo-espaciais como uma metodologia viável e confiável, para apresentar o desenho do arranjo futuro, da distribuição espacial dos elementos geográficos, em forma de mapas preditivos, para uma determinada área da superfície terrestre.

Por fim, se sugere que em trabalhos futuros, se façam aplicações desta proposta para outras finalidades, como uso em processos geomorfológicos, climáticos, hidrológicos, rurais. Ainda se sugere que se experimente utilizar parâmetros diferentes na geração deste modelo, como alterações no tipo de filtro que implementa o Autômato Celular (CA), o qual vai oferecer maior ou menor resistências as mudanças espaciais, por parte das células da grade, em que são 
A cartografia prospectiva e a geração de mapas preditivos do uso e cobertura da terra estudo de: caso perímetro urbano de Paranaguá

convertidos em meio digital, os mapas reais ou imagens que vão gerar os modelos têmporo-espaciais, no módulo CA-Markov do software IDRISI.

\section{REFERÊNCIAS}

ALMEIDA, C. M. Modelagem da dinâmica espacial como uma ferramenta auxiliar ao planejamento: simulação de mudanças de uso da terra em áreas urbanas para as cidades de Bauru e Piracicaba (SP). Tese de Doutorado do Curso da Pós-Graduação em Sensoriamento Remoto - São José dos Campos: INPE, 2003.

ALMEIDA, C.M; MONTEIRO, A.M.V; CÂMARA G. Perspectiva histórica de modelos de dinâmicas urbanas e regionais, in: Geoinformação em Urbanismo: cidade real $\mathbf{x}$ cidade virtual, São Paulo, Oficina de Textos, 2007.

BATTY, M.; XIE, Y.; SUN, Z. Modeling urban dynamics through GIS-based cellular automata. Computers, Environment and Urban Systems, v.23, p. 205-233, 1999.

BURROUGH, P.A; MCDONNELL, R.A. Principles of Geographical Information Systems, 2nd Edition. Oxford: Oxford University Press, 1998

CASTRO, M.L.A; CASTRO,R.O. Autômatos Celulares: Implementações de Von Neumann, Conway e Wolfram. Revista de Ciências Exatas e Tecnologia Vol. III, №. 3, Ano2008 p. 89-106. São Paulo, Anhanguera Educacional S. A, dezembro de 2008.

EASTMAN, J.R. IDRISI Andes - Tutorial, Clark University, Worcester, MA, p. 184187, 2006.

EASTMAN, J.R. Guide to Gis and Image Processing. Clark University, Worcester, MA, USA, 2003.

ECHENIQUE M. Urban systems, towards an explorative model (Land use and built form studies).UK, University of Cambridge Department of Architecture, 1968.

FERREIRA, J.C.; TENEDÓRI, J.A.; ROCHA, J.; SIMÕES, J. Modelos geográficos e sistemas complexos - Contributo para a monotorização da evolução da zona costeira. Disponível em: http://www.hidro.ufcg.edu.br/twiki/pub/ASUB/WebHome/ 942.pdf. Acessado em: 26/02/2010. 
A cartografia prospectiva e a geração de mapas preditivos do uso e cobertura da terra estudo de: caso perímetro urbano de Paranaguá

GREMONINI, L.; VICENTINI, E. Autômatos celulares: revisão bibliográfica e exemplos de implementações. Revista Eletrônica Lato Sensu - UNICENTRO, Ed. 6, p 3à 19, ano: 2008. Disponível em:http://web03.unicentro.br/especializacao/Revista _Pos/Lato_Sensu.htm.Acessado em 23/02/2010.

IBGE, Manual Técnico de Uso da Terra, 2ed. Ministério do Planejamento, Orçamento e Gestão, Rio de janeiro, 2006.

IBGE. Sinopse do Censo Demográfico 2010. Ministério do Planejamento, Orçamento e Gestão, Rio de Janeiro, 2011. index.htm, último acesso, 16/10/2011

OLMEDO, M.T.C. Métodos Avanzados en SIG. Dpto. de Análisis Geográfico Regional y Geografía Física. Universidad de Granada 12 y 13 de febrero de 2008

PÁDUA F.L.C; VIEIRA, N.J. Autômatos Celulares: Teoría e Aplicações. UFMG. Belo Horizonte - Janeiro de 2004.

PEDROSA B.M.; CÂMARA, G. Modelagem dinâmica e geoprocessamento; cap. 6, p.1-39, In: Druck, S.; Carvalho, M. S.; Câmara, G.; Monteiro, A. M. V. (eds). Análise Espacial de Dados Geográficos. Brasília, EMBRAPA, 2004.

PERES, O.M.; POLIDORI, M.C. Modelos Urbanos baseados em Autômatos Celulares: integrando ambiente natural e o crescimento urbano. Universidade Federal de Pelotas (UFPel), Pelotas-RS. Congresso da Sociedade Brasileiras de Computação, 2009. Disponível em: www.sbc.org.br/bibliotecadigital/ download.php? paper $=1455$. Acessado em: 25/02/2010.

RICOBOM, A.E, Metodologia auxiliar para revisão de planos diretores municipais através da aplicação da cartografia prospectiva: estudo de caso perímetro urbano de Paranaguá. 2012. Tese (doutorado) - Universidade Federal do Paraná, Setor de Ciências da Terra, Programa de Pós-Graduação em Geografia.

ROCHA, J; SOUSA, P.M.; TENEDÓRIO, J.A. Geosimulação e análise espacial: redes neuronais e autômatos celulares na previsão de alterações nos padrões de uso e ocupação do solo. Revista Inforgeo, 16/17, Lisboa, Edições Colibri, 2001/02, pp. 123-137. Disponível em: http://www.apgeo.pt/files/section44/1227097267

_Inforgeo_16_17_p127a141.pdf. Acessado em: 26/02/2010. 
A cartografia prospectiva e a geração de mapas preditivos do uso e cobertura da terra estudo de: caso perímetro urbano de Paranaguá

TENEDÓRIO, J.A.; ROCHA, J.; ENCARNAÇÃO, S.; FERREIRA, J.C. Modelos geográficos e sistemas complexos - Técnicas de geocomputação aplicadas à previsão de alterações na linha de costa. IX Encontro de Utilizadores de Informação Geográfica • USIG • Tagus Park, ESIG 2006.

TRAMUJAS, A. Histórias de Paranaguá - dos pioneiros da Cotinga à porta do Mercosul no Brasil Meridional. Paranaguá: Prefeitura Municipal de Paranaguá, 180 p. 1996. 